\title{
PENGARUH IKLIM ORGANISASI TERHADAP MOTIVASI KERJA PEGAWAI PADA PT. BANK MANDIRI KC LAPANGAN IMAM BONJOL PADANG
}

\author{
Hendra Wahyudi, Aminar Sutra Dewi \\ Sekolah Tinggi Ilmu Ekonomi KBP \\ hendra_wahyudi89@yahoo.co.id
}

\begin{abstract}
The purpose of this study was to analyze the influence of organization climate on employee motivation of Bank Mandiri KC Lapangan Imam Bonjol Padang. The sampling technique used is propotionate cluster random sampling, while the number of samples used for the analysis is 60 respondents. The data analysis technique used to test the hypothesis is simple linear regression. In research there is one variable, is organizational climate. Organizational climate significant influence on employee motivation of Bank Mandiri KC Lapangan Imam Bonjol Padang. While the value of correlation coefficient obtained in this study amounted is $49.2 \%$ These results show that, of employee motivation in Bank Mandiri KC Lapangan Imam Bonjol Padang, this shows that there is a very strong relationship between organization climate on on employee motivation of Bank Mandiri KC Lapangan Imam Bonjol Padang. While the remaining 50,8\% thought to be explained by other factors not examined in this study, such as leadership, organizational culture, orgnization commitment, and discipline. Based on the findings of a simple linear regression, it was found that the organizational climate as well as the positive influence on employee motivation of Bank Mandiri KC Lapangan Imam Bonjol Padang. This study provides practical recommendations for the management of Bank Mandiri KC Lapangan Imam Bonjol Padang to continue to improve organizational climate, because organizational climate have a significant impact on employee motivation of Bank Mandiri KC Lapangan Imam Bonjol Padang.
\end{abstract}

Keywords: Climate Organization and Work Motivation

PENDAHULUAN

Salah satu perusahaan perban kan yang tetap mempertahankan sumber daya manusia yang berkualitas adalah PT. Bank Mandiri KC Lapangan Imam Bonjol Padang. Pada saat ini, kondisi PT. Bank Mandiri KC Lapa ngan Imam Bonjol Padang menunjukan peningkatan signifikan. Hal ini masih menunjukkan adanya kendala pelaksa naan tujuan yang berkaitan dengan motivasi kerja karyawan.

Berdasarkan data yang dipero leh, dapat diketahui bahwa jumlah pegawai yang di promosikan dari tahun 2014 sampai dengan 2016 mengalami penurunan. Pada tahun 2014 jumlah pegawai yang di promosikan sebanyak 19 orang. Dan 
pada tahun 2015 jumlah pegawai yang di promosikan menurun menjadi 14 orang, sedangkan pada tahun 2016 jumlah pegawai yang di promosikan juga mengalami penurunan menjadi 9 orang.

Alasan dilakukan promosi jaba tan pada PT. Bank Mandiri KC Lapangan Imam Bonjol Padang, supaya dapat meningkatkan motivasi kerja pegawai tersebut. Sebaliknya, alasan tidak dilakukannya promosi pada pega wai yang lain, karena pegawai tersebut dinilai oleh atasannya tidak memiliki motivasi yang tinggi yang berdampak pada kinerja yang rendah. Hal ini sesuai dengan pendapat Martoyo (2006:71) "suatu motivasi yang menonjol yang mendorong seseorang untuk berparti sipasi aktif dalam suatu organisasi antara lain adalah kesempatan untuk maju". Setiap karyawan pada dasarnya sangat menginginkan untuk mendapat kan kesempatan dipromosikan. Karya wan yang dipromosikan akan mendapat kan status sosial yang lebih tinggi dan kompensasi (penerimaan upah/gaji) yang lebih besar dari yang mereka dapat pada jabatan sebelumnya, sehing ga karyawan akan merasa dihargai atas usaha yang mereka lakukan kepada perusahaan.

Berkaitan dengan hal tersebut, berdasarkan pengamatan dan survey yang dilakukan oleh peneliti, ternyata rendahnya motivasi kerja karyawan pada Bank Mandiri KC Lapangan Imam Bonjol Padang terjadi karena beberapa alasan berikut:

1) Kurangnya inisiatif pegawai dalam mengisi jam-jam kantor yang kosong atau ketika pimpinan sedang tidak berada dikantor.

2) Kurangnya dukungan organisasi pada pegawai dalam setiap menger jakan pekerjaan.

3) Ada beberapa pegawai yang belum melaksanakan tugas dengan sung guhsungguh, seperti bermalas-malasan dalam melaksanakan tugas.

4) Ada beberapa pegawai kurang bergairah dalam melaksanakan pekerjaan, hal ini terlihat dari tidak adanya kemauan dan kesenangan dalam melaksanakan pekerjaan dengan baik.

5) Ada beberapa pegawai yang kurang tergerak dalam melaksanakan suatu pekerjaan ini terlihat pada pegawai yang hanya rajin pada saat pimpi nan berada di kantor.

Menurut Herzberg dalam Siagian (2002), bahwa karyawan termotivasi untuk bekerja disebabkan oleh dua faktor: yaitu faktor intrinsik, dimana daya dorong yang timbul dari dalam diri masing-masing karyawan. Sedangkan yang kedua faktor ekstrinsik yaitu faktor pendorong yang datang dari luar diri seseorang terutama dari organisasi tempatnya bekerja. Faktor ekstrinsik ini mencakup: Administrasi dan kebijakan perusahaan, penyeliaan, gaji, hubungan antar pribadi, dan lingkungan kerja/iklim organisasi. Dari beberapa faktor yang mempengaruhi motivasi kerja, terdapat faktor lingku ngan kerja atau iklim organisasi. Wirawan (2007:121) mende-finisikan Iklim organisasi sebagai kualitas lingku ngan internal organisasi yang secara relatif terus berlangsung, dialami oleh anggota organisasi, mempengaruhi peri laku mereka dan dapat dilukiskan dalam pengertian satu set karakteristik atau sifat organisasi.

Berkaitan dengan hal tersebut, berdasarkan pengamatan yang penulis amati iklim organisasi yang ada pada PT. Bank Mandiri KC Lapangan Imam 
Bonjol Padang belum berkembang dengan baik sehingga menimbulkan rasa kurang nyaman yang mengindi kasikan tingkat motivasi pegawai belum tercapai dengan baik. Berda sarkan hasil prariset yang penulis lakukan, bahwa iklim organisasi pada PT. Bank Mandiri KC Lapangan Imam Bonjol Padang masih belum berkem bang dengan baik. Hal ini sejalan dengan beberapa fenomena yang penulis amati yaitu:

1) Suasana kerja karyawan yang belum kondusif.

2) Tingkat efektifitas komunikasi yang terjadi antar karyawan belum optimal yang berdampak kesalah pahaman antara karyawan.

3) Kebijakan dan peraturan yang diterapkan perusahaan, dimana tidak semua karyawan menerapkan aturan dan menerima kebijakan perusahaan.

Terjadinya penurunan motivasi kerja tersebut mungkin disebabkan oleh iklim organiasasi yang ada dalam perusahaan. Penelitian ini merupakan replikasi dari beberapa penelitian terdahulu yang dilakukan oleh Ferisca, dkk (2015), tentang pengaruh pengawa san dan iklim organisasi terhadap motivasi dan disiplin kerja pegawai pada kantor biro umum sekretariat daerah provinsi Riau. Dimana hasil penelitian menunjukkan bahwa iklim organisasi secara langsung memberikan pengaruh signifikan terhadap pening katan motivasi pegawai pada kantor Biro Umum Sekretariat Daerah Provinsi Riau. Penelitian tersebut memiliki persamaan dan perbedaan dengan penelitian ini. Persamaan penelitian ini dengan penelitian sebelumnya adalah sama-sama menco ba mencari pengaruh iklim organisasi. Sedangkan perbedaannya, penelitian ini mencoba untuk mencari pengaruh iklim organisasi dan pengawasan terhadap motivasi dan disiplin kerja. Perbedaan itu terutama dalam hal variabel penelitian, lokasi penelitian, jumlah sampel, pengujian hipotesis dan hasil penelitian.

Rumusan Masalah

Bagaimana pengaruh iklim organisasi terhadap motivasi kerja pegawai pada Bank Mandiri KC Lapangan Imam Bonjol Padang?

Tujuan Penelitian

Untuk menganalisis pengaruh iklim organisasi terhadap motivasi kerja pegawai pada Bank Mandiri KC Lapangan Imam Bonjol Padang.

\section{LANDASAN TEORI \\ Motivasi Kerja \\ Pengertian Motivasi Kerja}

Menurut Kadarisman (2013: 275) motivasi diartikan sebagai keseluruhan proses pemberian dorong an atau rangsangan kepada para karyawan sehingga mereka bersedia bekerja dengan rela tanpa dipaksa. Organisasi akan berhasil melaksanakan program-programnya bila orang-orang yang bekerja dalam organisasi dapat melaksanakan tugasnya dengan baik sesuai dengan bidang dan tanggung jawabnya masing-masing. Dalam mela ksanakan tugas tersebut, para pegawai perlu diberikan arahan dan dorongan sehingga potensi yang ada dalam dirinya dapat diubah menjadi prestasi yang menguntungkan organisasi. 


\section{Indikator Motivasi Kerja}

Sebagaimana teori Mas'ud (2004), indikator motivasi kerja berda sarkan teori tersebut dapat diuraikan sebagai berikut:

1. Kebutuhan rasa aman

2. Kebutuhan sosial

3. Kebutuhan harga diri

4. Kebutuhan Otonomi

5. Kebutuhan aktualisasi diri

\section{Iklim Organisasi}

\section{Pengertian Iklim Organisasi}

Lussier (2005:486) mengatakan bahwa iklim organisasi adalah persepsi pegawai mengenai kualitas lingkungan internal organisasi yang secara relatif dirasakan oleh anggota organisasi yang kemudian akan mempengaruhi perilaku mereka berikutnya.

\section{Indikator Iklim Organisasi}

Menurut Hoy dan Miskel (2001:431) indikator iklim organisasi terbagi menjadi dua macam, yaitu

1. Iklim Terbuka

2. Iklim Tertutup

\section{Hipotesis}

$\mathrm{H}_{1} \quad$ Diduga iklim organisasi berpe ngaruh signifikan dan positif terhadap motivasi kerja pada pegawai Bank Mandiri KC Lapangan Imam Bonjol Padang.

\section{METODE PENELITIAN}

\section{Populasi dan Sampel}

Di dalam penelitian ini yang menjadi populasi adalah seluruh karyawan PT. Bank Mandiri KC Lapangan Imam Bonjol Padang yang berjumlah 156 orang.

Melalui perhitungan dengan menggu nakan rumus slovin diatas maka jumlah responden sebagai sampel dalam penelitian ini adalah sebanyak 60 orang. Dalam penelitian ini teknik penarikan sampel yang digunakan adalah metode propotionate claster random sampling. Claster sampling menggambarkan bahwa sampel ditarik hanya dari salah satu kelompok saja.

\section{Teknik Analisis Data}

\section{Analisis Regresi Linier Sederhana}

Uji regresi linear sederhana merupakan teknik statistik yang digunakan untuk menguji pengaruh variabel bebas terhadap variabel terikat (Sekaran, 2006:299). Persamaan regresi linier sederhana adalah:

Di mana:

$$
\mathrm{Y}=\alpha+\beta_{1} \mathrm{X}_{1}
$$

$$
\begin{array}{ll}
\mathrm{Y} & =\text { Motivasi Kerja } \\
\alpha & =\text { Konstanta } \\
\beta_{1} & =\text { Koefisien Regresi } \\
\mathrm{X}_{1} & =\text { Iklim Organisasi }
\end{array}
$$




\section{Pengujian Hipotesis}

\section{Uji T-Statistik}

Uji t dilakukan untuk menguji apakah secara terpisah variabel independen mampu menjelaskan variabel dependen secara baik. Kriteria pengujian:

1) Jika t hitung $>$ t tabel, maka $\mathrm{H}_{0}$ ditolak dan $\mathrm{H}_{1}$ diterima.

2) Jika t hitung < t tabel, maka $\mathrm{H}_{0}$ diterima dan $\mathrm{H}_{1}$ ditolak.

3) Tingkat kepercayaan $\alpha$ untuk pengujian hipotesis adalah $95 \%$ atau $\alpha=0,05$

\section{HASIL PENELITIAN DAN PEMBAHASAN}

\section{Hasil Analisis Regresi Sederhana}

\section{Analisis Regresi Sederhana}

Uji regresi linear sederhana merupakan teknik statistik yang digunakan untuk menguji pengaruh variabel bebas terhadap variabel terikat. Hasil analisis regresi linier sederhana dapat diringkas pada Tabel 1 berikut ini:

Tabel 1

Ringkasan Hasil Analisis Regresi Linier Sederhana

\begin{tabular}{|c|l|c|}
\hline $\begin{array}{c}\text { Variabel } \\
\text { Terikat }\end{array}$ & \multicolumn{1}{|c|}{ Konstanta danVariabel Bebas } & Koefisien Regresi \\
\hline $\begin{array}{c}\text { Motivasi } \\
\text { Kerja }(\mathrm{Y})\end{array}$ & Konstanta $(\mathrm{a})$ & 1,269 \\
\cline { 2 - 3 } & Iklim Organisasi $\left(\mathrm{X}_{1}\right)$ & 0,604 \\
\hline
\end{tabular}

Sumber: Olahan Data Primer, Tahun 2016.

Berdasarkan hasil analisis regresi linier sederhana yang disajikan pada Tabel 1 di atas, berikut ini dapat dikemukakan persamaan regresi linier sederhana:

$$
Y=1,269+0,604 X_{1}
$$

Koefisisen regresi masing-masing variabel penelitian dapat diartikan sebagai berikut:

1. Nilai konstanta sebesar 1,269 berarti tanpa adanya pengaruh dari variabel bebas maka nilai variabel terikat hanya sebesar 1,269. Hal ini berarti bahwa apabila variabel bebas nilainya konstan (iklim organisasi), maka nilai variabel motivasi kerja sebesar 1,269.

2. Besaran koefisien regresi variabel iklim organisasi bernilai positif, bermakna jika variabel iklim organisasi mengalami kenaikan, maka motivasi kerja karyawan PT. Bank Mandiri KC Lapangan Imam Bonjol Padangakan mengalami peningkatan. Koefisien bernilai positif artinya terjadi hubungan positif antara iklim organisasi dengan motivasi kerja, semakin baik iklim organisasi, maka motivasi kerja akan semakin tinggi. Besaran koefisien regresi variabel iklim organisasi adalah 0,604 satuan. Hal ini bermakna bahwa jika terjadi peningkatan iklim organisasi sebesar satu satuan dengan asumsi variabel lain tetap, maka akan meningkatkan motivasi kerja sebesar 0,604 satuan.

\section{Hasil Pengujian Hipotesis dan Pembahasan}

Untuk melakukan uji hipotesis, dapat dilihat dari ringkasan hasil analisis regresi yang disajikan pada Tabel 2 sebagai berikut: 
Tabel 2

Hasil Uji T

\begin{tabular}{|l|l|c|c|}
\hline $\begin{array}{l}\text { Konstanta dan Variabel } \\
\text { Bebas }\end{array}$ & Sig. & $\propto$ & Kesimpulan \\
\hline Konstanta (a) & 0,000 & - & - \\
\hline Iklim Organisasi $\left(\mathrm{X}_{1}\right)$ & 0,000 & 0,005 & H1 Diterima \\
\hline
\end{tabular}

Sumber: Olahan Data Primer, Tahun 2016.

Pengaruh Iklim Organisasi terhadap Motivasi Kerja

Uji t digunakan untuk mengeta hui pengaruh variabel independen terha dap variabel dependen secara individu atau parsial. Hipotesis dalam penelitian ini iklim organisasi memiliki nilai signifikan sisebesar 0,000 , nilai signify kan tersebut lebih kecil dari alpha 0,05. Sedangkan besaran koefisien regresi variabel iklim organisasi adalah 1,269. Hal ini dapat diartikan bahwa iklim organisasi berpengaruh positif dan signifikan terhadap motivasi kerja karyawan pada PT. Bank Mandiri KC Lapangan Imam Bonjol Padang.

Menurut Herzberg dalam Siagian (2002), bahwa karyawan termo tivasi untuk bekerja disebabkan oleh dua faktor: yaitu faktor intrinsik,dimana daya dorong yang timbul dari dalam diri masing-masing karyawan. Sedang kan yang kedua faktor ekstrinsik yaitu faktor pendorong yang datang dari luar diri seseorang terutama dari organisasi tempatnya bekerja. Faktor ekstrinsik ini mencakup: Administrasi dan kebijakan perusahaan, penyeliaan, gaji, hubungan antar pribadi, dan lingkungan kerja /iklim organisasi. Dari beberapa faktor yang mempengaruhi motivasi kerja, terdapat faktor lingkungan kerja atau iklim organisasi.

Hal ini sesuai dengan penelitian yang dilakukan oleh Ferisca, dkk (2015), tentang pengaruh pengawasan dan iklim organisasi terhadap motivasi dan disiplin kerja pegawaipada kantor biro umum sekretariat daerah provinsi Riau. Dimana hasil penelitian menun jukkan bahwa iklim organisasi secara langsung memberikan pengaruh signify kan terhadap peningkatan motivasi pegawai pada kantor Biro Umum Sekretariat Daerah Provinsi Riau. Penelitian lain yang dilakukan oleh Ribka, dkk (2014), dengan judul pengaruh iklim organisasi terhadap motivasi kerja Aparatur Birokrasi di Manado. Dimana hasil penelitian menu njukkan bahwa iklim organisasi punya pengaruh positif dan korelasi tinggi dan signifikan terhadap motivasi kerja aparatur di Kantor Walikota Manado.

Penelitian Rofiatun dan Masluri (2011) tentang pengaruh iklim organisasi dan kompetensi pegawai terhadap kinerja pegawai dengan mediasi motivasi pada dinas-dinas di Kabupaten Kudus. Hasil penelitian tersebut menemukan bahwa adanya pengaruh iklim organisasi terhadap motivasi pegawai pada dinas-dinas di Kabupaten Kudus. Penelitian yang dilakukan oleh Deddy (2013) dengan judul pengaruh iklim organisasi terhadap kepuasan dan motivasi kerja karyawan Biro perjalanan wisata di Kota Bandung. Dimana hasil penelitian menunjukkan bahwa iklim organisasi punya pengaruh positif dan signifikan terhadapmotivasi kerja.

\section{Uji Koefisien Determinasi}

Dari proses pengujian koefisien determinasi yang telah dilakukan diperoleh ringkasan hasil seperti yang terlihat pada Tabel 3 berikut ini: 
Tabel 3

Hasil Pengujian Koefisien Determinasi

\begin{tabular}{l|c|r|r|r|r|}
\hline & & & \\
Model & $\mathrm{R}$ & $\mathrm{R}$ Square & $\begin{array}{c}\text { Adjusted R } \\
\text { Square }\end{array}$ & Std. Error of the Estimate & Durbin-Watson \\
\hline 1 & $.702^{\mathrm{a}}$ & .492 & .484 & .34386 & 1.232 \\
\hline
\end{tabular}
a. Predictors: (Constant), Iklim Organisasi
b. Dependent Variable: Motivasi Kerja

Sumber: Olahan Data Primer, Tahun 2016.

Dari hasil olahan data yang dapat dilihat pada Tabel 4.19, diketahui bahwa dari pengujian Koefisien Determinasi terlihat nilai Adjusted $R$ Square adalah sebesar 0,492 atau sama dengan 49,2\%. Hasil tersebut memper lihatkan bahwa dari motivasi kerja karyawan pada PT. Bank Mandiri KC Lapangan Imam Bonjol Padang yang dapat dijelaskan oleh iklim organisasi hanya sebesar 49,2\%, sedangkan sisanya $50,8 \%$ diduga dijelaskan oleh faktor-faktor lain yang tidak diteliti dalam penelitian ini, seperti gaya kepimimpinan, budaya organisasi, komitmen orgnaisasi, dan disiplin kerja.

\section{KESIMPULAN DAN SARAN}

\section{Kesimpulan}

1. Iklim organisasi berpengaruh positif dan signifikan terhadap motivasi kerja karyawan pada PT. Bank Mandiri KC Lapangan Imam Bonjol Padang.

2. Dari hasil pengolahan data dapat diketahui bahwa rata-rata variabel iklim organisasi adalah 3,63 dengan TCR sebesar 74,3\%. Hal ini bermakna bahwa iklim organisasi termasuk ke dalam kategori cukup baik.

3. Dari hasil pengolahan data dapat diketahui bahwa rata-rata variabel motivasi kerja adalah 3,68 dengan TCR sebesar 73,7\%. Hal ini bermakna bahwa Saran motivasi kerja termasuk ke dalam kategori cukup tinggi.

Hasil penelitian ini diharapkan akan memberikan kontribusi terhadap PT. Bank Mandiri KC Lapangan Imam Bonjol Padang. Dalam upaya mening katkan motivasi kerja di masa yang akan datang, maka disarankan kepada pihak manajemen perusahaan untuk terus berupaya memperhatikan iklim organisasi di perusahaan. Hal ini dise babkan karena iklim organisasi memiliki pengaruh yang berarti terhadap motivasi kerja karyawan. Maka disarankan kepada pihak mana jemen memperhatikan hal-hal sebagai berikut:

a. Berdasarkan hasil analisa deskriptif ditemukan bahwa pemberian ide/ gagasan dari karyawan untuk memperbaiki prestasi kerjamereka, memperoleh tingkat capaian jawa ban responden paling rendah. Berikut ini adalah beberapa hal yang harus diperhatikan: mencipta kan suatu pengaruh komunikasi, yakni: informasi kebawah yang terbuka dan cermat, kepercayaan dan pengambilan resiko, keterse diaan memberi dukungan, dan informasi keatas yang terus terang dan penuh perhatian. 
b. Berdasarkan hasil analisa deskriptif ditemukan bahwa karyawan merasa leluasa untuk melaksanakan peker jaan sebagai karyawan, memperoleh tingkat capaian jawaban responden paling rendah. Berikut ini adalah beberapa hal yang harus diperhati kan: perawatan fasilitas fisik, seperti menata sedemikian rupa pekarangan dan lingkungan organi sasi sehingga member kesan asri, teduh dan nyaman. Pentaan ruang kerja yang baik, dan penggunaan poster afrimasi seperti: poster yang berisi pesan-pesan positif diguna kan dan dipajang di berbagai tempat strategis yang mudah dan dapat selalu dilihat oleh pegawai. Poster afirmasi ini dapat digunakan untuk mensosialisasikan dan menanamkan pesan-pesan spiritual kepada selu ruh pegawai.

\section{DAFTAR PUSTAKA}

Aldi, Y., \& Susanti, F. (2019). Pengaruh Stress Kerja Dan Motivasi Kerja Terhadap Prestasi Kerja Karyawan Pada PT. Frisian Flag Indonesia Wilayah Padang. https://doi.org/10.31227/osf.io/et4rn

Aziz, N. (2019). Pengaruh Lingkungan Kerja Terhadap Kinerja Yang Dimediasi Oleh Motivasi Kerja Karyawan Rocky Plaza Hotel Padang. https://doi.org/10.17605/OSF.IO/E4C59

Deddy.2013.Pengaruh Iklim Organisasi Terhadap Kepuasan Dan Motivasi Kerja Karyawan Biro Perjalanan Wisata Di Kota Bandung. Bisnis Dan Mana jemen Aset Vol. 1 Oktober 2013

Ferisca Nurwidyanti, Marnis, dan Marzolina. 2015. Pengaruh Pe ngawasan Dan Iklim Organisasi Terhadap Motivasi Dan Disiplin Kerja Pegawai Pada Kantor Biro Umum Sekretariat Daerah Provinsi Riau.Vol. Vii No. 3 September 2015 Jurnal Tepak Manajemen Bisnis

Hoy, Wayne K., dan Miskel, Cecil G.2001. Educational Administr ation: Theory, Research, and Practice, Singapore: McGraw-Hill.

Kadarisman. 2013. Manajemen Pengem bangan Sumber Daya Manusia. Jakarta: PT. Raja Grafindo Persada.

Lussier, N Robert, 2005. Human Relations in Organization Applications and skill Building. New York: Mc Graw Hill.

Mayliza, R. (2019). Pengaruh Kompensasi Finansial, Lingkungan Kerja Dan Motivasi Kerja Terhadap Kinerja Pegawai Pada Kantor PDAM Kota Payakumbuh. https://doi.org/10.17605/OSF.IO/DZXAF

Mayliza, R. (2019). Pengaruh Gaya Kepemimpinan Dan Disiplin Kerja Terhadap Kinerja Karyawan Dengan Motivasi Kerja Sebagai Variabel Intervening Pada PT. Semen Padang. https://doi.org/10.17605/OSF.IO/FYPQ9. 
Ribka S. M, Florence Daicy J. L, dan Sonny Rompas.2014. Pengaruh Iklim Organisasi terhadap Moti vasi Kerja Aparatur Birokrasi (suatu studi diKantor Walikota Manado). Jurnal Administrasi Publik.Http://Ejournal.Unsrat.Ac.Id/Index.Php/Jap/Issue/View/760 Vol. 3 No. 4.2014

Ridho, M., \& Susanti, F. (2019). Pengaruh Stres Kerja Dan Motivasi Kerja Terhadap Kepuasan Kerja Pada Karyawan Bank Mandiri Syariah Cabang Padang. https://doi.org/10.31227/osf.io/pa2cg

Rivai. Veithzal. 2004. Manajemen Sumber Daya Manusia Untuk Perusahaan: Dari Teori Ke Praktik. PT. Raja Grafindo Persada, Jakarta.

Robbins, Stephen P. 2003. Perilaku organisasi. Jakarta : PT. Indeks Kelompok GRAMEDIA.

Rofiatun Dan Masluri. 2011. Pengaruh Iklim Organisasi Dan Kompeten si Pegawai Terhadap Kinerja Pegawai Dengan Mediasi Moti vasi pada Dinas-Dinas Di Kabupaten Kudus. ISSN: 14411 -1799 Analisis Manajemen Vol. 5 No. 1 Juli 2011

Sekaran, Uma. 2006. Research Meth ods For Business, Edisi Keem pat. Salemba Empat: Jakarta

Simamora, Henry, 2004, Manajemen Sumber Daya Manusia, Edisi Ketiga, Cetakan Pertama, Bagi an Penerbitan STIE YKPN, Yogyakarta.

Umar, Husein.2008, Desain Penelitian MSDM dan Perilaku Karyawan, Seri Desain Penelitian Bisnis - No 1, PT Rajagrafindo Persada Jakarta. 